\title{
Is There a Role for Second Generation Antipsychotics in the Treatment of PTSD?
}

\section{Gerardo Villarreal ${ }^{\star}$}

Department of Psychiatry and Neuroscience, University of New Mexico, R. G. Murphy VA Medical Center, San Pedro Dr SE. Albuquerque NM, USA

*Corresponding author: Gerardo Villarreal, Department of Psychiatry and Neuroscience, University of New Mexico, R.G. Murphy VA Medical Center, 1501 San Pedro Dr SE. Albuquerque NM 87108, USA, Tel: + 505-265-1711; E-mail: gvillarr@salud.unm.edu

Rec date: November 04, 2017; Acc date: November 20, 2017; Pub date: November 22, 2017

Copyright: (c) 2017 Villarreal G. This is an open-access article distributed under the terms of the creative commons attribution license, which permits unrestricted use, distribution, and reproduction in any medium, provided the original author and source are credited.

\section{Description}

Posttraumatic Stress Disorder (PTSD) is common in civilians and veterans and is often chronic and disabling [1\&2]. The Selective Serotonin Reuptake Inhibitors (SSRIs) and venlafaxine are considered first line treatment for PTSD although only sertraline and paroxetine have FDA approval [3]. These medications have been shown to improve most PTSD symptoms and in particular, irritability [4\&5]. However, they have little effect on insomnia [4\&5] which is serious problem in PTSD patients [6]. Military veterans tend to have little or no response to antidepressant medications [7-10]. Second Generation Antipsychotics (SGAs) are often used in the treatment of PTSD, particularly for insomnia [11]. A review of SGAs randomized trials in the treatment of PTSD found the most evidence of benefit from quetiapine and risperidone, particularly for re-experiencing and hyperarousal symptoms [12].

However, a large Veterans Administration (VA) funded trial of risperidone as an adjunct medication in military veterans unresponsive to SSRI's found it was no better than placebo for global PTSD severity, although a post-hoc analysis did show improvement in re-experiencing and hyperarousal symptoms, this was not considering clinically significant [13]. A randomized, placebo-controlled trial of quetiapine as single agent in PTSD, found significant improvement on global PTSD symptom severity and also for experiencing and hyperarousal clusters [14].

Significant improvement was seen in measures of anxiety and depression [14]. A post hoc analysis of data from that trial found the strongest effect was on insomnia (unpublished data). These findings are consistent with anecdotal evidence, a survey of 2613 Veterans Administration providers found that quetiapine was the most frequently prescribed atypical antipsychotic to veterans with PTSD (47\%). The reasons for prescribing quetiapine was its perceived efficacy, particularly for sleep and sedation [11].

Therefore, there is a rationale to use SGAs, in particular quetiapine, in the treatment of PTSD, since its benefit on insomnia may complement the effect if antidepressants on irritability. The main limitation of SGA are their metabolic side effects, including changes in insulin sensitivity and lipid metabolism, which increase the risk metabolic syndrome, type 2 diabetes and cardiovascular disease [15]. The new VA/DoD practice guidelines emphasize the use of exposurebased therapies and recommend against using SGAs in PTSD [3].

Clinicians treating patients with PTSD, in particular those with chronic and severe symptoms face a predicament. These patients are often unable or unwilling to engage in exposure-based therapies and there is evidence of high dropout rates and low engagement in these therapies in real-world settings [16]. Only 2 medications are FDA- approved for the treatment of PTSD and in general few pharmacological interventions are recommended [3]. Prescribers often utilize off-label medications [17].

The SGAs, in particular quetiapine, may have a role in the treatment of selected PTSD cases with severe insomnia and other hyperarousal and re-experiencing symptoms; the benefit of SGAs may complement the effect of SSRIs on irritability. Close monitoring of metabolic parameters, weight and BMI is advised. In cases with early weight gain behavioral interventions targeting nutrition and exercise counseling should be considered, since they have been effective in lowering weight and BMI in patients with schizophrenia taking SGAs $[18,19]$. Metformin has been useful in this regard [20] and thus should be considered when these medications are used, and weigh grain is evident. The SGAs and quetiapine may have a role in treating PTSD but should be reserved for treatment-resistant and severe PTSD cases.

\section{References}

1. Kessler RC (2000) Posttraumatic stress disorder: The burden to the individual and to society. J Clin Psychiatry 61: 4-12.

2. Hoge CW, Castro CA, Messer SC, McGurk D, Cotting DI, et al. (2004) Combat duty in Iraq and Afghanistan, mental health problems, and barriers to care. N Engl J Med 351: 13-22.

3. https://www.healthquality.va.gov/guidelines/MH/ptsd/cpg_PTSDfull-201011612.PDF

4. Davidson JR, Landerman LR, Farfel GM, Clary CM (2002) Characterizing the effects of sertraline in post-traumatic stress disorder. Psychol Med 32: 661-670.

5. Stein DJ, Pedersen R, Rothbaum BO, Baldwin DS, Ahmed S, et al. (2009) Onset of activity and time to response on individual CAPS-SX17 items in patients treated for post-traumatic stress disorder with venlafaxine ER: a pooled analysis. Int J Neuropsychopharmacol 12: 23-31.

6. Pigeon WR, Campbell CE, Possemato K, Ouimette P (2013) Longitudinal relationships of insomnia, nightmares, and PTSD severity in recent combat veterans. J Psychosom Res 75: 546-550.

7. Van Der Kolk BA, Dreyfuss D, Michaels M, Shera D, Berkowitz R, et al. (1994) Fluoxetine in posttraumatic stress disorder. J Clin Psychiatry 55: 517-522.

8. Hertzberg MA, Feldman ME, Beckham JC, Kudler HS, Davidson JR (2000) Lack of efficacy for fluoxetine in PTSD: A placebo controlled trial in combat veterans. Ann Clin Psychiatry 12: 101-105.

9. Zohar J, Amital D, Miodownik C, Kotler M, Bleich A, et al. (2002) Double-blind placebo-controlled pilot study of sertraline in military veterans with posttraumatic stress disorder. J Clin Psychopharmacol 22: 190-195.

10. Friedman MJ, Marmar CR, Baker DG, Sikes CR, Farfel GM (2007) Randomized, double-blind comparison of sertraline and placebo for posttraumatic stress disorder in a Department of Veterans Affairs setting. J Clin Psychiatry 68: 711-720. 
Citation: Villarreal G (2017) Is There a Role for Second Generation Antipsychotics in the Treatment of PTSD?. J Trauma Treat 6: 406. doi: $10.4172 / 2167-1222.1000406$

Page 2 of 2

11. Hermes E, Sernyak M, Rosenheck R (2014) The use of second generation antipsychotics for post-traumatic stress disorder in a US Veterans Health Administration Medical Center. Epidemiol Psychiatr Sci 23: 281-288.

12. Ahearn EP, Juergens T, Cordes T, Becker T, Krahn D (2011) A review of atypical antipsychotic medications for posttraumatic stress disorder. Int Clin Psychopharmacol 26: 193-200.

13. Krystal JH, Rosenheck RA, Cramer JA, Vessicchio JC, Jones KM, et al. (2011) Adjunctive risperidone treatment for antidepressant-resistant symptoms of chronic military service-related PTSD: A randomized trial. JAMA 306: 493-502.

14. Villarreal G, Hamner MB, Cañive JM, Robert S Calais LA, et al. (2016) Efficacy of quetiapine monotherapy in posttraumatic stress disorder: A randomized, placebo-controlled trial. Am J Psychiatry 173: 1205-1212.

15. Newcomer JW (2007) Antipsychotic medications: Metabolic and cardiovascular risk. J Clin Psychiatry 68: 8-13.
16. Najavits LM (2015) The problem of dropout from "gold standard" PTSD therapies. F1000Prime Rep 7: 43.

17. Mohamed S, Rosenheck RA (2008) Pharmacotherapy of PTSD in the U.S. Department of Veterans Affairs: Diagnostic- and symptom-guided drug selection. J Clin Psychiatry 69: 959-965.

18. Vreeland B, Minsky S, Menza M, Rigassio Radler D, Roemheld-Hamm B, et al. (2003) A program for managing weight gain associated with atypical antipsychotics. Psychiatr Serv 54: 1155-1157.

19. Centorrino F, Wurtman JJ, Duca KA, Fellman VH, Fogarty KV, et al. (2006) Weight loss in overweight patients maintained on atypical antipsychotic agents. Int J Obes (Lond) 30: 1011-1016.

20. Mizuno Y, Suzuki T, Nakagawa A, Yoshida K, Mimura M, et al. (2014) Pharmacological strategies to counteract antipsychotic-induced weight gain and metabolic adverse effects in schizophrenia: a systematic review and meta-analysis. Schizophr Bull 40: 1385-1403. 